Herbert Schneider (Mainz)

\title{
Zum Gedenken an Wolfgang Suppan (1933-2015)
}

Am 4. Mai 2015 verstarb Wolfgang Suppan nach längerer Krankheit in Graz. Er gehörte der Generation an, die nach dem Zusammenbruch des Dritten Reichs gewisse Verzögerungen ihrer Ausbildung in Kauf nehmen musste. Suppan erhielt seine musikalische Ausbildung am Steiermärkischen Landeskonservatorium und studierte an der Universität Graz die Fächer Musikwissenschaft, Volkskunde und Philosophie, an einer Universität, die wie Suppan betonte, noch von der Humboldt'schen Tradition geprägt war. Seine Karriere verlief dank seiner Begabung, seiner wissenschaftlichen Orientierung und seines organisatorischen Geschicks sehr geradlinig. Nach der Promotion bei Hellmut Federhofer über Heinrich Eduard Josef von Lannoy (1959, Teilveröffentlichung 1960) erhielt er ein Stipendium der DFG, das ihn nach Freiburg führte, wo er am Institut für ostdeutsche Volkskunde und am Volksliedarchiv tätig war. Nach seiner Habilitation in Mainz (1971, seine Schrift Deutsches Musikleben zwischen Renaissance und Barock erschien 1973) verstand er es, Studierende mit "Spartakus-Denken“ in seinen Lehrveranstaltungen für seinen anthropologischen Ansatz und die komparatistische Sicht von Musikkulturen einschließlich außereuropäischer Naturvolk- und Hochkulturen zu begeistern und sich damit zugleich von den Mainzer Kollegen zu distanzieren. Nach der Berufung an das Institut für Musikethnologie der Kunst-Universität Graz im Jahre 1974 setzte Suppan seine intensiven Forschungen und zahllosen organisatorischen Initiativen fort und publizierte eine Fülle von Büchern, Aufsätzen und Editionen. Erwähnt seien die Buchreihen Musikethnologische Sammelbände, Alta Musica und Musica Pannonica.

Suppan war der Doyen der österreichischen Musikethnologie. Seine vier Forschungsschwerpunkte waren die Steirische Landeskundliche Musikforschung (u. a. Steirisches Musiklexikon, ${ }^{2}$ 2009), die vokale und instrumentale Volksmusik, d. h. die Europäische Musikethnologie und Vergleichende Musikwissenschaft, die Blasmusik und die Anthropologie der Musik, die er als „praktische Anthropologie“ bezeichnete. Die Verbindung von Praxis und Wissenschaft hatte ihm sein Lehrer Federhofer vorgelebt. Historische und ethnologische Musikwissenschaft zu verknüpfen, war sein besonderes Anliegen. Charakteristisch für die spezifische Einschätzung seines Fachgebietes ist sein Urteil in den „autobiographischen Notizen“ der ihm gewidmeten zweiten Festschrift (2010), die Dominanz der Historischen Musikwissenschaft gereiche dem Gesamtfach Musikwissenschaft zum Schaden.

Suppan war prägendes Mitglied mehrerer wissenschaftlicher Gesellschaften (u. a. des International Folk Music Council) und engagierte sich vielfach in Verbänden (Bund Deutscher Blasmusikverbände, Deutscher Musikrat, International Society for Music Education der Unesco etc.). Er hat Gastvorträge in Amerika, in Israel und in Dänemark gehalten und war u. a. Träger des Großen Ehrenzeichens des Landes Steiermark, des Bundesverdienstkreuzes I. Klasse des Verdienstordens der Bundesrepublik Deutschland und des Großen Silbernen Ehrenzeichens für Verdienste um die Republik Österreich. 